\title{
ИНДИКАТОРНЫЕ ПОКАЗАТЕЛИ СОСТОЯНИЯ ЭКОСИСТЕМ В ЭЛЕМЕНТНОМ СОСТАВЕ ВОЛОС ЖИТЕЛЕЙ РАЙОНОВ СЕВЕРНОГО КАЗАХСТАНА
}

\author{
Байкенова Гулим Еркиновна1, \\ guliander@bk.ru
}

\author{
Барановская Наталья Владимировна², \\ nata@tpu.ru
}

Какабаев Ануарбек Аязбаевич1,
anuarka@mail.ru

Берсимбаев Рахметкажы Искендирович³, ribers@mail.ru

Корогод Наталья Петровна 4 ,
natalya_korogod@mail.ru

\section{Наркович Дина Владимировна², narkovich@tpu.ru}

\author{
Куровская Влада Владиславовна², \\ kurovskaya@tpu.ru \\ 1 Кокшетауский университет им. Ш. Уалиханова, \\ Республика Казахстан, 020000, г. Кокшетау, ул. Абая, 76. \\ 2 Национальный исследовательский Томский политехнический университет, \\ Россия, 634050, г. Томск, пр. Ленина, 30. \\ 3 Евразийский Национальный университет им. Л.Н. Гумилева, \\ Республика Казахстан, 010008, г. Нур-Султан, ул. Кажымукана, 13. \\ 4 Павлодарский педагогический университет, \\ Республика Казахстан, 140002, г. Павлодар, ул. Мира, 60.
}

\begin{abstract}
Актуальность работы обосновывается необходимостью оценки экологической ситуации на территориях уранодобывающих и других предприятий по добыче полезных ископаемых. Таким регионом, где наблюдается высокая заболеваемость и смертность населения от злокачественных новообразований, является Северный Казахстан. На изучаемой территории находится одна из крупнейших урановорудных провинций в Казахстане - Северо-Казахстанская урановорудная провинция. Она расположена в Акмолинской и Северо-Казахстанской областях. В качестве индикатора изменения экологогеохимического состояния территории использовали элементый состав волос населения.

Цель: оценка уровней накопления химических элементов в волосах жителей районов Северного Казахстана.

Методы. Определение 73 химических элементов в волосах было произведено методом масс-спектрометрического анализа с индуктивно связанной плазмой (ICP-MS) в лаборатории Проблемной научно-исследовательской лаборатории гидрогеохимии Томского политехнического университета.

Результаты. Был изучен элементный состав волос жителей двух районов Северного Казахстана и проведен сравнительный анализ с другими территориями региона и отдельными областями России. Анализ показал, что в Акмолинской и СевероКазахстанской областях отмечено высокое содержание натрия, а также редких, редкоземельных и радиоактивных (тория и урана) элементов. Установлено концентрирование специфичных для эколого-геохимических условий региона элементов, в частности золота, висмута, селена. Выявлено наличие общих элементов для всех исследуемых территории Казахстана и Pоссии: $\mathrm{Au}, \mathrm{Ag}$, Se u Hg.
\end{abstract}

\section{Ключевые слова:}

Биоиндикатор, волосы, химические элементы, Северный Казахстан, элементный статус, техногенез.

\section{Введение}

Территория Республики Казахстан представляет собой уникальную биогеохимическую провинцию, сформированную в результате присутствия крупнейших месторождений полиметаллического и неметаллического сырья, а также их разработки [1]. Одним из регионов, в котором отмечены экологические проблемы, связанные, в частности, с освоением урановоруд- ных объектов, является территория Северного Казахстана. Для этой территории характерными являются высокие показатели уровня заболеваемости и смертности населения от злокачественных опухолей и в целом неблагоприятная медико-экологическая обстановка [2].

В настоящее время на севере Казахстана осуществляется добыча урана на месторождениях Сeмизбай и Восток, которые расположены на террито- 
рии Северо-Казахстанской урановорудной провинции. В административном отношении в данную провинцию входят Акмолинская и Северо-Казахстанская области. Эти регионы характеризуются сложной радиоэкологической ситуацией, обусловленной повышенной радиоактивностью, связанной как с наличием высокорадиоактивных гранитов, так и с многолетней деятельностью уранодобывающих и других предприятий по добыче полезных ископаемых [3].

Для региона, где добывался уран и другая руда, необходимы исследования, которые могли бы позволить эффективно оценить экологическую ситуацию данной территории и сделать выводы о ее влиянии на организм человека. Для этого исследователи в разных странах зачастую используют биологические материалы человека, как правило волосы, кровь, ногти, мочу и некоторые другие, которые могут быть индикатором изменения окружающей среды [4-6]. Многими учеными было доказано, что использование волос в анализе эколого-токсикологических корреляций является эффективным $[7,8]$. Это подтверждается и Международным агентством по атомной энергии (МАГАТЭ), которое оказывает помощь в проведении координированных исследований $[9,10]$.

Химический состав волос человека формируется под влиянием ряда факторов, что необходимо учитывать при их использовании в качестве индикаторного объекта [11]. Изучением данного вопроса занимаются исследователи в разных странах мира. Исследователи из США, например, выявили, что пары токсичных элементов (As-Cd, As-Se, $\mathrm{Pb}-\mathrm{As}$ и $\mathrm{Se}-\mathrm{Cd}$ ) сильно коррелировали в волосах курящих людей, но не коррелировали в волосах некурящих, что позволяет предположить, что сигаретный дым является распространенным источником токсичных элементов в волосах населения [12]. Многие авторы подчеркивают, что основными предикторами ртути в волосах человека являются загрязненный воздух, а также потребление рыбы и курение [13-18]. На формирование элементного состава влияют патологические состояния. Исследования, которые провели российские ученые, показали, что у детей с расстройством аутистического спектра содержание эссенциальных элементов в волосах и крови понижено, а уровень токсичных микроэлементов наоборот повышен [19]. Данные, полученные исследователями из России, подтверждают гипотезу о том, что $\mathrm{Mg}$, $\mathrm{Mn}$ и $\mathrm{Zn}$ могут играть значительную роль в развитии расстройства аутистического спектра и неврологического-поведенческого расстройства развития у детей [20]. Также установлено, что нет корреляции между содержанием свинца и развития расстройства аутистического спектра [21] Некоторые результаты исследований показали, что болезнь Кашина-Бека отражается дефицитом селена в волосах [22]. Ученые из Турции провели обсервационное исследование связи мышьяка и селена в волосах и ногтях людей с заболеванием Альцгеймера, в результате которого было выявлено, что уровни содержания As и Se были выше у пациентов с данным заболеванием, чем у контрольной группы. [23]. Китайские ученые исследовали концентрирование тория и урана в волосах беременных женщин. В результате данного исследования выяснилось, что содержание тория коррелирует с патологией и, соответственно, может быть фактором риска ротолицевой расщелины у потомства, а в противовес этому уран не является причиной данного заболевания [24]. В результате проведенного биомониторинга волос и крови жителей, проживающих в непосредственной близости от бывшего Семипалатинского испытательного ядерного полигона и вблизи промышленных предприятий восточного и северо-восточного региона Казахстана, было выявлено, что проживание в районе бывшего Семипалатинского полигона можно считать безопасным, в то время как экологическое состояние промышленных поселений представляется довольно неблагоприятным из-за повышенного уровня токсичных металлов в биосубстратах [25]. Хорватские и российские ученые установили что, анализ мультибиоэлементного профиля волос может иметь особое значение в эпидемиологии питания, персонализированной медицине и при изучении хронических физических и психических заболеваний, а также позволяет предвидеть более сложные структурные метаболические особенности и изучение внутренней организации и интеграции одновременно происходящих биометаболических жизненных процессов в организме человека [26]. Волосы обладают уникальным потенциалом для раскрытия ретроспективной информации. Японские исследователи обнаружили, что определение количества таллия в образцах волос, разделенных на последовательные сегменты, дает ценную информацию о периоде воздействия, даже если после влияния проходит значительное время [27].

Если кровь и моча являются мгновенными индикаторами ежедневного поступления элементов, то волосы указывают на хроническое воздействие на них, соответствующее периоду роста и длине. Это позволяет использовать данные об элементном составе волос для определения индекса нагрузки на организм и необходимого уровня питательных веществ [28].

Элементный статус человека может зависеть от места проживания и экологической обстановки региона $[11,29]$. Элементный состав волос часто используется для целей экологического районирования территории [30].

Сложные ткани эпидермального происхождения, которыми являются волосы, накапливают химические элементы в высоких концентрациях. Также неинвазивность и простота подготовки их для анализа - невероятное преимущество данного биологического материала для проведения эколого-геохимического районирования территорий [30].

В целом, несмотря на полифакторный характер формирования элементного состава волос человека, его можно применять в качестве биоиндикатора изменения эколого-геохимического состояния территории. Для этого необходимо изучение регионального фона, а также проведение сравнительного анализа по другим территориям. Большинство факторов, оказывающих влияние на изменение элементного состава волос, можно исключить на стадии пробоотбора. 
Цель нашего исследования - оценка уровней накопления химических элементов в волосах жителей районов Северного Казахстана и выявление региональных особенностей, сформированных в условиях уникальной полиметаллической биогеохимической провинции.

\section{Материалы и методы}

Отбор волос производился на территории Северного Казахстана осенью 2018 г. Всего исследовано 33 образца. Пробы взяты у населения СевероКазахстанской и Акмолинской областей. В выборку включены люди без вредных привычек, постоянно проживающие на данной территории, без патологий. При отборе фиксировали полное имя, адрес проживания, возраст, пол и место рождения. В выборку включены жители абсолютно здоровые, без хронических и острых воспалительных процессов, а также достаточно долгое время (не менее 10 лет) проживающие непосредственно там, где производился отбор. Волосы были отобраны и прошли подготовку к анализу согласно рекомендациям МАГАТЭ $[10,30]$. Материал отобран хирургическими ножницами из нержавеющей стали с пяти точек головы. Затем волосы упаковывались в полиэтиленовые пакетики с фиксатором. На внешнюю сторону пакетиков с фиксатором клеилась маркированная этикетка.

Пробоподготовка проводилась на кафедре географии, экологии и туризма в Кокшетауском государственном университете им. Ш. Уалиханова и в отде- лении геологии Томского политехнического университета.

Методом масс-спектрометрии с индуктивносвязанной плазмой (ICP-MS) было определено содержание 73 химических элементов [31]. Работа выполнялась в Проблемной научно-исследовательской лаборатории гидрогеохимии Томского политехнического университета (заведующая лабораторией к.г.м.н. А.А. Хващевская).

Обработка полученных данных производилась посредством программ Microsoft Excel и STATISTICA 10.

Критическое значение коэффициентов корреляции определялось в соответствии с табличными значениями, исходя из количества проб в выборке, согласно рекомендациям [32]. Для Северного Казахстана при 33 пробах критическое значение коэффициента корреляции составляет 0,45 при достоверности 99,0 \% [11].

\section{Результаты исследования и их обсуждение}

Полученную выборку волос по территории Северного Казахстана было решено рассмотреть с позиции административного деления территории. Мы изучили данные по результатам анализа волос жителей двух регионов Северного Казахстана - Акмолинской и Северо-Казахстанской областей. Сравнительный анализ среднеарифметических содержаний элементов с другими районами Казахстана и отдельными территориями России (Кемеровская, Томская и Читинская области) показал существенные различия в накоплении отдельных химических элементов (табл. 1).

Таблица 1. Оченочные уровни накопления химических элементов в волосах человека (мг/кг сухого вещества)

Table 1. Estimated levels of accumulation of chemical elements in human hair ( $\mathrm{mg} / \mathrm{kg}$ dry matter)

\begin{tabular}{|c|c|c|c|c|c|c|}
\hline $\begin{array}{c}\text { Элементы } \\
\text { Elements }\end{array}$ & $\begin{array}{c}\text { Акмолинская } \\
\text { область, } \\
\text { Akmola region, } \\
\mathrm{n}=22\end{array}$ & $\begin{array}{c}\text { Северо- } \\
\text { Казахстанская } \\
\text { область, } \\
\text { North Kazakhstan } \\
\text { region, } \mathrm{n}=11\end{array}$ & $\begin{array}{c}\text { Казахстан, } \\
\text { г. Экибастуз, } \\
\text { Kazakhstan, } \\
\text { Ekibastuz, n=10 }\end{array}$ & $\begin{array}{c}\text { Россия, } \\
\text { Томская область, } \\
\text { Russia, } \\
\text { Tomsk region, } \\
\text { n=32 } \\
\end{array}$ & $\begin{array}{c}\text { Россия, } \\
\text { Кемеровская } \\
\text { область, } \\
\text { Russia, Kemerovo } \\
\text { region, } \mathrm{n}=23\end{array}$ & $\begin{array}{c}\text { Россия, } \\
\text { Читинская } \\
\text { область } \\
\text { Russia, Chita } \\
\text { region, } \mathrm{n}=5\end{array}$ \\
\hline $\mathrm{Li}$ & $0,05 \pm 0,01$ & $0,04 \pm 0,01$ & $0,003 \pm 0,001$ & 0,29 & 0,16 & 0,05 \\
\hline $\mathrm{Be}$ & $0,03 \pm 0,01$ & $0,02 \pm 0,005$ & $0,001 \pm 0,0003$ & 0,01 & 0,04 & 0,015 \\
\hline $\mathrm{B}$ & $1,9 \pm 0,3$ & $1,45 \pm 0,32$ & н.д. & н.д. & 1,43 & 3,64 \\
\hline $\mathrm{Na}$ & $553 \pm 112$ & $480 \pm 106$ & $70 \pm 15$ & 414 & 186 & 417 \\
\hline $\mathrm{Mg}$ & $223 \pm 38,4$ & $299 \pm 74$ & $90 \pm 28$ & 2356 & 94 & 353 \\
\hline $\mathrm{Al}$ & $11 \pm 3$ & $3,89 \pm 1,67$ & $11 \pm 2$ & 36 & 37 & 13 \\
\hline $\mathrm{Si}$ & $135 \pm 18$ & $189 \pm 46,4$ & н.д. & 241 & н.Д. & 315 \\
\hline $\mathrm{P}$ & $150 \pm 7$ & $127 \pm 5,3$ & $117 \pm 5$ & 1796 & 215 & 154 \\
\hline $\mathrm{S}$ & $106200 \pm 7335$ & $113606 \pm 9859$ & н.д. & н.д. & н.Д. & Н.Д. \\
\hline $\mathrm{Cl}$ & $2649 \pm 483$ & $1957 \pm 683$ & н.д. & н.д. & н.Д. & Н.Д. \\
\hline $\mathrm{K}$ & $315 \pm 87$ & $249 \pm 134$ & $50 \pm 17$ & 9996 & 113 & 549 \\
\hline $\mathrm{Ca}$ & $1682 \pm 298$ & $1830 \pm 441$ & $1370 \pm 447$ & 19552 & 1324 & 1678 \\
\hline $\mathrm{Sc}$ & $0,05 \pm 0,005$ & $0,05 \pm 0,005$ & н.д. & 0,35 & 0,37 & 0,11 \\
\hline $\mathrm{Ti}$ & $1,1 \pm 0,3$ & $0,71 \pm 0,2$ & $1,4 \pm 1,2$ & 7,6 & 110 & 2,7 \\
\hline $\mathrm{V}$ & $0,07 \pm 0,01$ & $0,06 \pm 0,01$ & $0,04 \pm 0,005$ & 0,1 & 0,3 & 0,1 \\
\hline $\mathrm{Cr}$ & $0,5 \pm 0,05$ & $0,52 \pm 0,05$ & $0,41 \pm 0,03$ & 4,5 & 6,2 & 3 \\
\hline $\mathrm{Mn}$ & $2,2 \pm 0,36$ & $2,75 \pm 1,12$ & $1,5 \pm 0,3$ & 13,7 & 1,9 & 5,9 \\
\hline $\mathrm{Fe}$ & $22 \pm 4$ & $14 \pm 1,9$ & $13 \pm 1,2$ & 75 & 56 & 28 \\
\hline $\mathrm{Co}$ & $0,19 \pm 0,06$ & $0,21 \pm 0,07$ & $0,03 \pm 0,01$ & 0,5 & 0,1 & 0,01 \\
\hline $\mathrm{Ni}$ & $0,97 \pm 0,25$ & $0,7 \pm 0,27$ & $0,6 \pm 0,3$ & 0,9 & 1,9 & 0,9 \\
\hline $\mathrm{Cu}$ & $16,2 \pm 2,7$ & $12,5 \pm 1,33$ & $9,0 \pm 1,5$ & 16,1 & 14,9 & 10,3 \\
\hline $\mathrm{Zn}$ & $328 \pm 49$ & $288 \pm 86$ & $455 \pm 130$ & 133 & 162 & 133 \\
\hline $\mathrm{Ga}$ & $0,03 \pm 0,007$ & $0,02 \pm 0,008$ & $0,004 \pm 0,001$ & 0,022 & 0,014 & 0,006 \\
\hline $\mathrm{Ge}$ & $0,07 \pm 0,004$ & $0,04 \pm 0,01$ & $0,02 \pm 0,001$ & 0,004 & 0,011 & 0,01 \\
\hline As & $0,07 \pm 0,01$ & $0,04 \pm 0,007$ & $0,04 \pm 0,02$ & 0,17 & 0,55 & 0,16 \\
\hline $\mathrm{Se}$ & $1,43 \pm 0,3$ & $0,87 \pm 0,22$ & $0,44 \pm 0,03$ & 0,98 & 0,76 & 0,48 \\
\hline $\mathrm{Br}$ & $1,9 \pm 0,3$ & $1,42 \pm 0,33$ & н.д. & 32,1 & н.Д. & 4,3 \\
\hline $\mathrm{Rb}$ & $0,14 \pm 0,05$ & $0,12 \pm 0,06$ & $0,03 \pm 0,01$ & 4,16 & 0,11 & 0,46 \\
\hline
\end{tabular}


Известия Томского политехнического университета. Инжиниринг георесурсов. 2021. Т. 332. № 7. 148-158 Байкенова Г.Е. и др. Индикаторные показатели состояния экосистем в элементном составе волос жителей районов ...

\begin{tabular}{|c|c|c|c|c|c|c|}
\hline $\mathrm{Sr}$ & $12 \pm 2,3$ & $14 \pm 3,6$ & $6 \pm 2$ & 27,6 & 2,9 & 4,8 \\
\hline $\mathrm{Y}$ & $0,02 \pm 0,009$ & $0,01 \pm 0,003$ & $0,003 \pm 0,001$ & 0,014 & 0,016 & 0,011 \\
\hline $\mathrm{Zr}$ & $0,07 \pm 0,01$ & $0,12 \pm 0,07$ & $0,14 \pm 0,04$ & 0,2 & 0,48 & 0,45 \\
\hline $\mathrm{Nb}$ & $0,04 \pm 0,0009$ & $0,03 *$ & $0,0005 \pm 0,0001$ & 0,027 & 0,005 & 0,004 \\
\hline Mo & $0,04 \pm 0,007$ & $0,05 \pm 0,007$ & $0,04 \pm 0,006$ & 0,11 & 0,04 & 0,04 \\
\hline $\mathrm{Ru}$ & $0,01 \pm 0,0002$ & $0,01 \pm 0,003$ & н.д. & н.д. & н.д. & 0,005 \\
\hline $\mathrm{Rh}$ & $0,005 \pm 0,002$ & $0,004 \pm 0,002$ & н.д. & н.Д. & н.Д. & н.д. \\
\hline $\mathrm{Pd}$ & $0,01 \pm 0,002$ & $0,009 \pm 0,004$ & н.д. & н.д. & н.д. & н.д. \\
\hline $\mathrm{Ag}$ & $0,4 \pm 0,2$ & $0,54 \pm 0,17$ & $0,08 \pm 0,02$ & 1 & 0,2 & 2,9 \\
\hline $\mathrm{Cd}$ & $0,22 \pm 0,12$ & $0,17 \pm 0,09$ & $0,04 \pm 0,01$ & 0,13 & 0,09 & 0,25 \\
\hline In & $0,03 \pm 0,003$ & $0,03 \pm 0,004$ & $0,001 \pm 0,0002$ & 0,004 & 0,001 & 0,003 \\
\hline $\mathrm{Sn}$ & $0,5 \pm 0,2$ & $0,4 \pm 0,16$ & $0,3 \pm 0,06$ & 0,72 & 0,71 & 1,71 \\
\hline $\mathrm{Sb}$ & $0,07 \pm 0,02$ & $0,07 \pm 0,03$ & $0,02 \pm 0,006$ & 0,05 & 0,45 & 0,07 \\
\hline $\mathrm{Te}$ & $0,1 \pm 0,016$ & $0,13 \pm 0,02$ & $0,005^{*}$ & 0,009 & 0,005 & 0,004 \\
\hline I & $1,18 \pm 0,33$ & $0,7 \pm 0,24$ & н.д. & 1,9 & н.д. & 0,3 \\
\hline Cs & $0,01 \pm 0,002$ & $0,01 \pm 0,002$ & $0,001 \pm 0,00001$ & 0,006 & 0,004 & 0,004 \\
\hline $\mathrm{Ba}$ & $2,4 \pm 1,26$ & $1,5 \pm 0,49$ & $2,1 \pm 0,6$ & 11,63 & 3,14 & 3,05 \\
\hline $\mathrm{La}$ & $0,02 \pm 0,005$ & $0,01 \pm 0,002$ & $0,005 \pm 0,001$ & 0,026 & 0,02 & 0,022 \\
\hline $\mathrm{Ce}$ & $0,03 \pm 0,009$ & $0,02 \pm 0,003$ & $0,01 \pm 0,002$ & 0,038 & 0,038 & 0,045 \\
\hline $\operatorname{Pr}$ & $0,004 \pm 0,001$ & $0,001 \pm 0,0004$ & $0,001 \pm 0,0001$ & 0,005 & 0,004 & 0,003 \\
\hline $\mathrm{Nd}$ & $0,02 \pm 0,005$ & $0,01 \pm 0,001$ & $0,003 \pm 0,001$ & 0,009 & 0,013 & 0,015 \\
\hline $\mathrm{Sm}$ & $0,01 \pm 0,001$ & $0,01 \pm 0,002$ & $0,001 \pm 0,00005$ & 0,002 & 0,002 & 0,002 \\
\hline $\mathrm{Eu}$ & $0,01 \pm 0,001$ & $0,01 \pm 0,002$ & $0,0002 \pm 0,000002$ & 0,001 & 0,001 & 0,001 \\
\hline $\mathrm{Gd}$ & $0,01 \pm 0,002$ & $0,005 \pm 0,002$ & $0,001 \pm 0,0001$ & 0,002 & 0,003 & 0,006 \\
\hline $\mathrm{Tb}$ & $0,01 \pm 0,002$ & $0,01 \pm 0,002$ & $0,001 *$ & 0,001 & 0,001 & 0,001 \\
\hline Dy & $0,004 \pm 0,001$ & $0,005 \pm 0,002$ & $0,001 \pm 0,00001$ & 0,001 & 0,002 & 0,002 \\
\hline Ho & $0,004 \pm 0,002$ & $0,01 \pm 0,003$ & $0,0002^{*}$ & 0,0004 & 0,001 & 0,001 \\
\hline $\mathrm{Er}$ & $0,007 \pm 0,002$ & $0,008 \pm 0,003$ & $0,001 *$ & 0,001 & 0,003 & 0,001 \\
\hline $\mathrm{Tm}$ & $0,01 \pm 0,002$ & $0,009 \pm 0,002$ & $0,001 *$ & 0,0005 & 0,0004 & 0,001 \\
\hline $\mathrm{Yb}$ & $0,01 \pm 0,001$ & $0,01 \pm 0,002$ & $0,001 *$ & 0,001 & 0,001 & 0,001 \\
\hline $\mathrm{Lu}$ & $0,01 \pm 0,002$ & $0,01 \pm 0,002$ & $0,001 *$ & 0,0004 & 0,0004 & 0,001 \\
\hline $\mathrm{Hf}$ & $0,03 \pm 0,006$ & $0,03 \pm 0,007$ & $1,34 \pm 0,5$ & 0,004 & 0,009 & 0,009 \\
\hline $\mathrm{Ta}$ & $0,01 \pm 0,001$ & $0,02 \pm 0,001$ & $0,001 *$ & 0,003 & 0,004 & 0,001 \\
\hline $\mathrm{W}$ & $0,03 \pm 0,002$ & $0,03^{*}$ & $0,02 \pm 0,003$ & 0,21 & 0,05 & 0,11 \\
\hline $\mathrm{Re}$ & $0,006 \pm 0,002$ & $0,002 \pm 0,0001$ & н.д. & н.д. & 0,0002 & 0,001 \\
\hline Os & $0,02 \pm 0,001$ & $0,02 \pm 0,002$ & н.д. & н.д. & н.д. & н.д. \\
\hline $\mathrm{Ir}$ & $0,015 \pm 0,002$ & $0,01 \pm 0,002$ & н.д. & н.д. & н.д. & н.д. \\
\hline $\mathrm{Pt}$ & $0,008 \pm 0,002$ & $0,007 \pm 0,003$ & $0,007 \pm 0,005$ & 0,01 & 0,002 & н.д. \\
\hline $\mathrm{Au}$ & $0,06 \pm 0,01$ & $0,12 \pm 0,06$ & $0,009 \pm 0,002$ & 0,016 & 0,006 & 0,049 \\
\hline $\mathrm{Hg}$ & $0,24 \pm 0,05$ & $0,22 \pm 0,04$ & $0,2 \pm 0,05$ & 0,48 & 0,21 & 0,23 \\
\hline $\mathrm{Tl}$ & $0,005 \pm 0,002$ & $0,008 \pm 0,003$ & $0,0003 \pm 0,0001$ & 0,001 & 0,001 & 0,005 \\
\hline $\mathrm{Pb}$ & $1,55 \pm 0,45$ & $0,72 \pm 0,29$ & $1,1 \pm 0,4$ & 1,91 & 2,09 & 4,35 \\
\hline $\mathrm{Bi}$ & $0,62 \pm 0,6$ & $0,02 \pm 0,007$ & $0,004 \pm 0,002$ & 0,23 & 0,06 & 0,19 \\
\hline Th & $0,02 \pm 0,0009$ & $0,02 \pm 0,0007$ & $0,001 \pm 0,0001$ & 0,003 & 0,003 & 0,004 \\
\hline $\mathrm{U}$ & $0,32 \pm 0,067$ & $0,3 \pm 0,09$ & $0,2 \pm 0,04$ & 0,014 & 0,031 & 0,015 \\
\hline
\end{tabular}

Примечание: * - предел определения, содержание элемента ниже предела; среднее арифметическое содержание \pm стандартная ошибка среднего; н.д. - нет данных.

Note: * -detection limit, the content of the element is below the limit; mean \pm standard error of mean; $н . \partial .-$ no data.

Так, для территории Северного Казахстана характерно более высокое содержание $\mathrm{Na}, \mathrm{In}, \mathrm{Te}, \mathrm{Cs}, \mathrm{Sm}, \mathrm{Eu}$, $\mathrm{Tb}, \mathrm{Yb}, \mathrm{Lu}, \mathrm{Ta}, \mathrm{Th}$ как по сравнению с российскими областями, так и в отношении районов Казахстана - города Экибастуза в Павлодарской области. В Акмолинской, Северо-Казахстанской и Павлодарской областях встречаются в повышенных концентрациях такие элементы, как Hf и U. Эколого-геохимическая ситуация Северного Казахстана влияет на более высокое концентрирование радиоактивных, редкоземельных и редких элементов, что отражает природно-техногенную специфику региона исследования. Урановая специализация Павлодарской области, по-видимому, обусловлена поступлением этого элемента с водой, в составе которой отмечается его высокое содержание по данным изучения накипи питьевых вод [33].

В отличие от регионов Казахстана для Томской области наблюдается высокое содержание $\mathrm{Mg}, \mathrm{P}, \mathrm{K}$,
$\mathrm{Fe}, \mathrm{Br}, \mathrm{Rb}, \mathrm{Sr}$ и Ba. В волосах жителей Кемеровской области концентрируются в большей степени $\mathrm{Al}, \mathrm{Ti}$, $\mathrm{Cr}$. Максимальное содержание B, Si, Ag, Sn, Pb отмечено в Читинской области. Высокое накопление данных элементов на территорий российских областей объясняется как эколого-геохимической ситуацией природного характера, так и значительным влиянием техногенеза на локальных территориях $[34,35]$.

Для выявления региональной геохимической специфики природной среды активно используют показатели коэффициентов концентрации, получаемые относительно условного фона или установленного среднего для выборки. Данные, полученные нами при нормировании на среднее арифметическое для волос жителей Северного Казахстана, позволили установить региональную особенность волос населения двух областей (рис. 1).

Очевидно, что даже две близлежащих области значимо отличаются по концентрированию элементов 
в составе волос жителей. Так, в отличие от СевероКазахстанской области в Акмолинской концентрируются такие элементы, как $\mathrm{Bi}, \mathrm{Pr}, \mathrm{Al}, \mathrm{Pb}, \mathrm{Ce}, \mathrm{Nd}$, I, Ti, $\mathrm{Fe}, \mathrm{Ba}, \mathrm{Ni}, \mathrm{B}, \mathrm{Cu}, \mathrm{As}, \mathrm{Br}, \mathrm{Y}, \mathrm{Cd}, \mathrm{Sn}, \mathrm{Li}$, Нf более значимо. B то же время выявляется общий спектр элементов, характерных для двух территорий. К ним относятся $\mathrm{Na}$, $\mathrm{Mg}, \mathrm{Ca}$ - элементы, биологическая роль которых весьма значима в организме человека. Кроме того, установлена высокая концентрация кремния, который может характеризовать пылевую составляющую, оказывающую влияние на формирование элементного соста- ва данного биосубстрата. Специфика формирования геохимической составляющей волос населения хорошо демонстрируют геохимические ряды:

- Акмолинская область - $\mathrm{Bi}_{1,41}>\mathrm{Pr}_{1,28}>\mathrm{Al}_{1,23}>\mathrm{Pb}_{1,21}>$ $\mathrm{Ce}_{1,19}>\mathrm{Nd}_{1,16}=\mathrm{I}_{1,16}>\mathrm{Ti}_{1,13}=\mathrm{Fe}_{1,13}=\mathrm{Ba}_{1,13}>\mathrm{Ni}_{1,1}>\mathrm{B}_{1,08}=$

$\mathrm{Cu}_{1,08}=\mathrm{As}_{1,08}=\mathrm{Br}_{1,08}>\mathrm{Y}_{1,07}=\mathrm{Cd}_{1,07}=\mathrm{Sn}_{1,07}>\mathrm{Li}_{1,05}=$

$\mathrm{Hf}_{1,05}>\mathrm{P}_{1,04}=\mathrm{Zn}_{1,04}>\mathrm{Rb}_{1,03}=\mathrm{Sb}_{1,03}=\mathrm{Hg}_{1,03}>\mathrm{U}_{1,02}>\mathrm{V}_{1,01}=$ $\mathrm{La}_{1,01}>\mathrm{Na}_{1}=\mathrm{Mg}_{1}=\mathrm{Si}_{1}=\mathrm{S}_{1}=\mathrm{Cl}_{1}=\mathrm{K}_{1}=\mathrm{Ca}_{1}$.

- Северо-Казахстанская область $-\mathrm{Si}_{1,27}>\mathrm{Zr}_{1,26}>\mathrm{Ag}_{1,22}>$ $\mathrm{Sr}_{1,2}>\mathrm{Mg}_{1,18}>\mathrm{Mn}_{1,14}>\mathrm{Ca}_{1,09}>\mathrm{Sc}_{1,05}>\mathrm{Co}_{1,04}>\mathrm{Na}_{1}$.

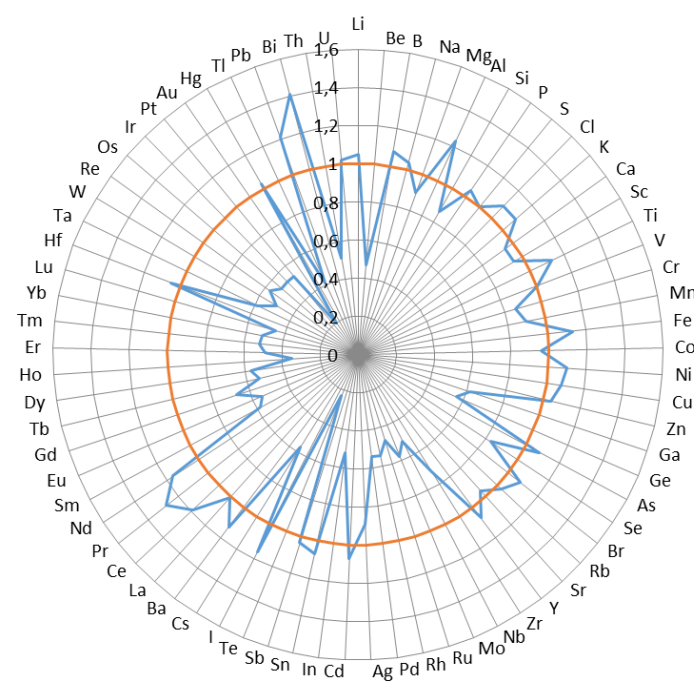

$a / a$

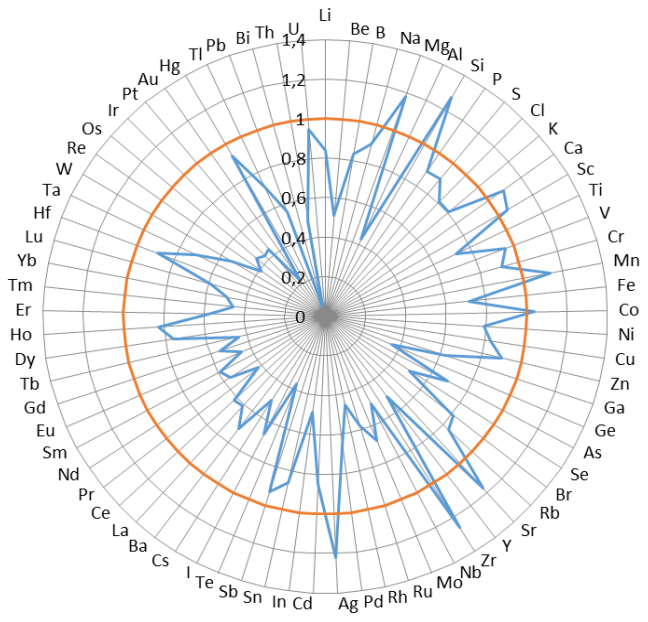

$\sigma / b$

Рис. 1. Геохимическая специализация волос жителей Акмолинской (а) и Северо-Казахстанской (б) областей относительно регионального среднего

Fig. 1. Geochemical specialization of the hair of residents of Akmola (a) and North Kazakhstan (b) regions in relation to the regional average levels

Таблица 2. Биогеохимическая специфика волос населения Акмолинской и Северо-Казахстанской областей и других регионов относительно кларка ноосферы

Table 2. Biogeochemical specificity of hair of the population of Akmola and North Kazakhstan regions and other regions relative to the clarke of the noosphere

\begin{tabular}{|c|c|}
\hline Регион/Region & $\begin{array}{c}\text { Геохимический } \\
\text { ряд/Geochemical series }\end{array}$ \\
\hline $\begin{array}{l}\text { Акмолинская область } \\
\text { Akmola region }(\mathrm{N}=22)\end{array}$ & $\begin{array}{c}\mathrm{Bi}_{97}>\mathrm{Au}_{87}>\mathrm{S}_{62,5}>\mathrm{Te}_{15,6}>\mathrm{Re}_{12,8}> \\
\mathrm{Ag}_{8}>\mathrm{Zn}_{7}>\mathrm{Se}_{5}>\mathrm{Ir}_{4}>\mathrm{I}_{2}>\mathrm{Cd}_{1,4}>\mathrm{Hg}_{1,3}\end{array}$ \\
\hline $\begin{array}{l}\text { Северо-Казахстанская область } \\
\text { North-Kazakhstan region }(\mathrm{N}=11)\end{array}$ & $\begin{array}{c}\mathrm{Au}_{174}>\mathrm{S}_{66,8}>\mathrm{Te}_{20,3}>\mathrm{Ag}_{10}>\mathrm{Zn}_{6,3}>\mathrm{R} \\
\mathrm{e}_{4,3}>\mathrm{Bi}_{3,12}>\mathrm{Se}_{3,1}>\mathrm{Ir}_{2,6}>\mathrm{I}_{1,3}>\mathrm{Hg}_{1,2}> \\
\mathrm{Cd}_{1,06}\end{array}$ \\
\hline $\begin{array}{l}\text { Павлодарская область, } \\
\text { Экибастуз } \\
\text { Pavlodar region, Ekibastuz (N=10) }\end{array}$ & $\mathrm{Au}_{13}>\mathrm{Zn}_{10}>\mathrm{Ag}_{1,6}>\mathrm{Se}_{1,57}>\mathrm{Hg}_{1,1}$ \\
\hline $\begin{array}{l}\text { Томская область } \\
\text { Tomsk region }(\mathrm{N}=32)\end{array}$ & $\begin{array}{c}\mathrm{Bi}_{36}>\mathrm{Au}_{23,2}>\mathrm{Ag}_{20}>\mathrm{P}_{3,6}>\mathrm{I}_{3,5}=\mathrm{Se}_{3,5}> \\
\mathrm{Zn}_{2,9}>\mathrm{Hg}_{2,7}>\mathrm{Te}_{1,4}>\mathrm{Br}_{1,23}>\mathrm{Ca}_{1,22}\end{array}$ \\
\hline $\begin{array}{l}\text { Кемеровская область } \\
\text { Kemerovo region }(\mathrm{N}=23)\end{array}$ & $\mathrm{Bi}_{9,3}>\mathrm{Au}_{8,7}>\mathrm{Ag}_{4}>\mathrm{Zn}_{3,5}>\mathrm{Se}_{2,7}>\mathrm{Hg}_{1,2}$ \\
\hline $\begin{array}{l}\text { Читинская область } \\
\text { Chita region }(\mathrm{N}=5)\end{array}$ & $\begin{array}{c}\mathrm{Au}_{71}>\mathrm{Ag}_{58}>\mathrm{Bi}_{29,7}> \\
\mathrm{Zn}_{2,9}>\mathrm{Re}_{2,1}>\mathrm{Se}_{1,7}>\mathrm{Cd}_{1,5}>\mathrm{Hg}_{1,3}\end{array}$ \\
\hline
\end{tabular}

Примечание: коэффициенты концентрачии рассчитаны только для тех элементов, которые представлены в работе М.А. Глазовской [36].

Note: The concentration ratios are calculated only for elements represented in the work of M.A. Glazovskaya [36].
Элементная специфика волос населения Акмолинской и Северо-Казахстанской областей и других регионов преимущественно сохраняется при нормировании относительно других показателей, например, кларка ноосферы, что представлено в табл. 2.

Проведенный анализ показал, что содержание химических элементов в волосах жителей Акмолинской и Северо-Казахстанской областей относительно кларка ноосферы [36] имеет высокую концентрацию золота, что обусловлено деятельностью предприятий по добыче золота в Северном Казахстане. Остаются максимальными концентрации висмута, ртути, а также йода, специфика накопления которых обусловлена природными особенностями изучаемой территории, учитывая ее геологическую составляющую и наличие высокоминерализованных соленых вод. Также накопления таких элементов, как: S, Te, $\mathrm{Re}, \mathrm{Ag}, \mathrm{Zn}$, Se, Ir, Cd, свидетельствуют о влиянии природной геолого-геохимической составляющей и возможного влияния техногенных источников на их поступление.

Для волос жителей города Экибастуза характерным является концентрирование $\mathrm{Au}, \mathrm{Zn}, \mathrm{Ag}, \mathrm{Se}, \mathrm{Hg}$. А отличительной чертой волос населения российских регионов является накопление висмута, золота, сере- 
бра, фосфора, йода, селена, цинка, ртути, теллура, брома и кальция в Томской, висмута, золота, серебра, цинка, селена, ртути в Кемеровской, серебра, золота, висмута, цинка, рения, селена, кадмия, ртути в Читинской областях. Специфичными элементами для Северных областей Казахстана и областей Российской Федерации, а также для города Экибастуз являются золото, серебро, селен и ртуть. При этом коэффициент концентрации золота серьезно варьирует с весьма существенным увеличением в волосах жителей именно Северо-Казахстанской области, достигая значения свыше сотни. Наличие селена в волосах жи- телей двух областей Северного Казахстана связано с присутствием этого элемента в урановых рудах.

В целом предприятия угольной и топливноэнергетической промышленности вносят большой вклад в загрязнение атмосферы. При сжигании угля в атмосферу поступают значительные количества селена, а из атмосферы возвращаются в виде пылевых выпадений, что объясняется присутствием данного элемента в волосах жителей г. Экибастуз.

Еще более ярко особенности изученных волос проявляются при рассмотрении корреляционных взаимосвязей химических элементов (рис. 2).

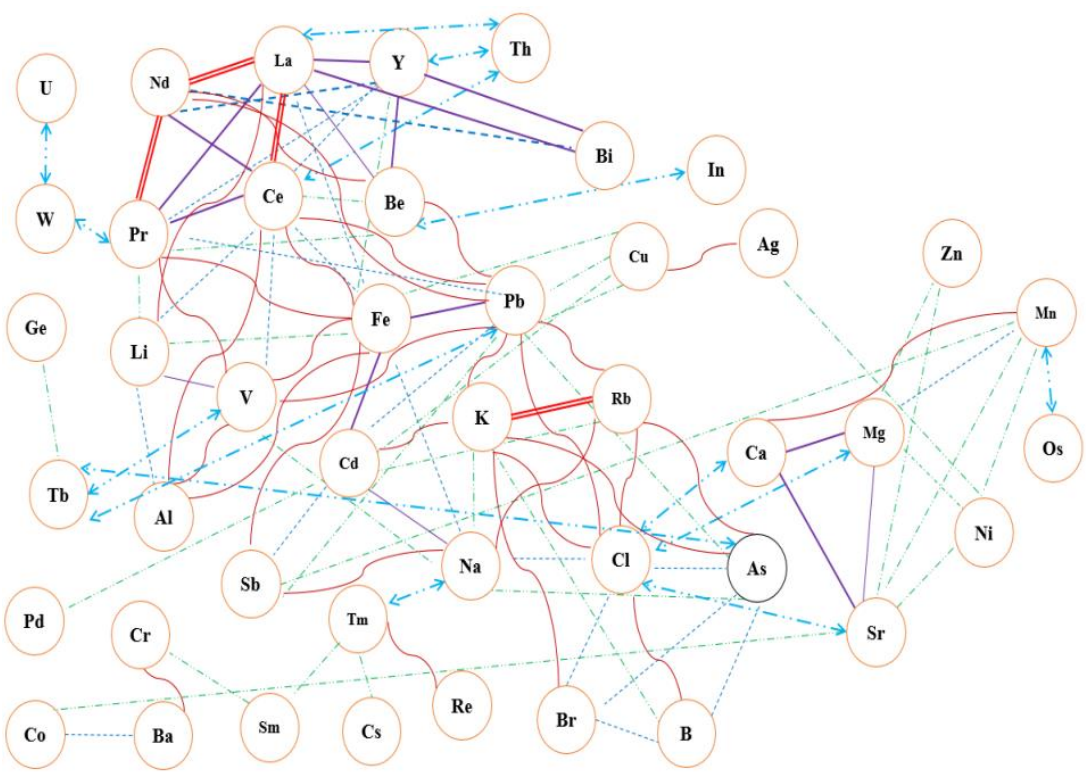

Рис. 2. Ассочиативные связи элементов в волосах жителей Северного Казахстана

Fig. 2. Associative links of elements in the resident's hair of Northern Kazakhstan

Территория Северного Казахстана характеризуется наличием обширных корреляционных взаимосвязей между элементами в волосах жителей. Сравнения с характером корреляционных взаимодействий элементов для волос жителей других регионов, имеющихся в литературных источниках, свидетельствует о существенной специфике, которая выражается как в наличии весьма обширных взаимосвязей, так и в их индивидуальности. Так, например, для волос жителей территории расположения хвостохранилищ горнорудного производства в Кемеровской области $[34,35]$ характерны взаимосвязи между элементами, определяющими геохимический фон территории.

Установлена прямая корреляция между легкими редкоземельными элементами и их отрицательной связью с торием и с другими элементами, прямая корреляция между рубидием и калием. Известно, что рубидий в виде изоморфной примеси присутствует в минералах калия - мусковите, микроклине, ортоклазе. Эти минералы легко разносятся ветром, поэтому данные связи, скорее всего, указывают на возможное влияние фактора пыления на формирование состава волос. По видимому, на формирование ассоциаций во многом оказывает влияние наличие на территории определенных геологических формаций. Так, напри- мер, крупнейшее месторождение золота в Зерендинском районе Акмолинской области (Васильковское), разрабатываемое карьерным способом, можно считать как природным, так и техногенным объектом, активно влияющим на концентрирование химических элементов в волосах населения. Рудными минералами являются арсенопирит, халькопирит, висмутин и некоторые другие, том числе самородные золото и висмут. Главный рудный минерал - арсенопирит - содержит основную массу золота. Элементы, входящие в состав рудных минералов, образуют тесные взаимосвязи и в составе волос населения Северного Казахстана, что свидетельствует о значительной роли природного фактора.

В целом данные по изучению особенностей элементного состава волос жителей двух областей Северного Казахстана позволили установить ориентировочные средние содержания химических элементов, которые могут являться базовыми в дальнейших эколого-геохимических исследованиях. На наш взгляд, основным фактором формирования элементного состава волос жителей изученного региона являются металлогенические особенности территории и специфика подземных вод, а техногенная составляющая незначительна. 


\section{Заключение}

В результате проведенных исследований на территории Северного Казахстана были установлены оценочные уровни накопления химических элементов в составе волос населения двух областей - Акмолинской и Северо-Казахстанской. Полученные данные о средних содержаниях 73-х химических элементов, изученных методом ИСП-МС, могут являться оценочными в дальнейших эколого-геохимических исследованиях.

Концентрирование определенного спектра элементов относительно кларковых и среднестатистических показателей в волосах населения Северного Казахстана показывает влияние металлогенических особенностей территории и специфики подземных вод как основных факторов формирования их элементного состава. Роль техногенной составляющей является незначительной.

\section{СПИСОК ЛИТЕРАТУРЫ}

1. Панин М.С. Экология Казахстана. - Семипалатинск: СемГПУ, 2005. $-548 \mathrm{c}$.

2. Какабаев А.А. Цитогенетическая оценка уровня мутагенеза у рабочих уранодобывающей промышленности Северного Казахстана: дис. .... канд. биол. наук. - Алматы, 2000. - 125 с.

3. Беркинбаев Г.Д., Федоров Г.В., Бенсман В.А. Обращение с радиоактивными отходами в Казахстане // Экология и промышленность Казахстана. - 2013. - № 2 (38). - С. 42-49.

4. Ковальский В.В. Геохимическая среда и жизнь. - М.: Наука, 1987. $-76 \mathrm{c}$.

5. Baranovskaya N.V., Shvetsova D.V., Rikhvanov L.P. Element content in children hair samples (Tomsk Region, Russia) // Trace Elements in Human: New Perspectives: Proc. of the 7th Intern. Symp. - Athens, Greece, 2009. - P. 290-303.

6. Геохимия окружающей среды / Ю.Е. Сает, Б.А. Ревич, Е.П. Янин, А.И. Ачкасов, И.Л. Башаркевич, Т.Л. Онищенко, Л.Н. Павлова, С.Ш. Саркисян, Р.С. Смирнова, Н.Я. Трефилова. - М.: Недра, 1990. - 335 с.

7. Кист А.А. Феноменология биогеохимии и бионеорганической химии. - Ташкент: ФАН, 1987. -235 с.

8. Kist A.A., Zhuk L.I. Human hair composition and the problems of global ecology. - Tashkent, USSR: Institute of Nuclear Physics of the Uzbek Academy of Sciences, 1991. - $60 \mathrm{p}$.

9. Ryabukhin Yu.S. Activation analysis of hair as an indicator of contamination of man by environmental trace element pollutants. Vienna: IAEA, 1978. - $134 \mathrm{p}$

10. Element analysis of biological materials. Current problems and techniques with special reference to trace elements // App. II. Technical reports series. № 197. - Vienna: IAEA, 1980 - P. 351-367.

11. Влияние техногенеза на формирование элементного состава волос детского населения / Д.В. Наркович, Н.В. Барановская, Е.В. Коваль, Н.П. Корогод // Известия Томского политехнического университета. - 2016. - Т. 327. - № 8. - С. 116-128.

12. Environmental biomonitoring of essential and toxic elements in human scalp hair using accelerated microwave-assisted sample digestion and inductively coupled plasma optical emission spectroscopy H. Kumakli, A.V. Duncan, K. McDaniel, T.F. Mehari, J. Stephenson, L. Maple, Z. Crawford, C.L. Macemore, C.M. Babyak, S.O. Fakayode // Chemosphere. - 2017. - V. 174. - P. 708-715.

13. Biomonitoring of mercury in hair of children living in the Valencian Region (Spain). Exposure and risk assessment / R. Perez, T. Suelves, Y. Molina, F. Corpas-Burgos, V. Yusà // Chemosphere. - 2019. - V. 217. - P. 558-566.

14. Biomonitoring of mercury in hair of breastfeeding mothers living in the Valencian Region (Spain). Levels and predictors of exposure / V. Yusà, R. Pérez, T. Suelves, F. Corpas-Burgos, M. Gormáz, P. Dualde, C. Coscolla, J. Quiles, M. Roca, M. Vento // Chemosphere. - 2017. - V. 187. - P. 106-113.

15. Human exposure assessment to mercury through hair analysis in coastal villages of the Valparaiso region (Chile) / M.A. Bravo, S. Parra, W. Quiroz, A. Neaman // Journal of the Chilean Chemical Society. - 2019. - V. 64. - P. 4480-4483.
Анализ корреляционных взаимосвязей химических элементов в составе волос жителей региона позволяет сделать предположение о влиянии пылевой составляющей на их поступление.

В целом проведенные исследования позволили сделать вывод о наличии как общей составляющей в элементном составе волос человека вне зависимости от региона проживания, так и о специфичном концентрировании химических элементов для каждой территории, что подтверждает возможность использования данного объекта в качестве индикатора экологогеохимического состояния.

Работа выполнена при частичной финансовой поддержке грантов РНФ № 20-67-47005 и 20-67-47021 в проведении аналитических исследований проб, отобранных на территории Читинской области.

16. Hair mercury concentrations and associated factors in an electronic waste recycling area, Guiyu, China / Wenqing Ni, Yaowen Chen, Yue Huang, Xiaoling Wang, Gairong Zhang, Jiayi Luo, Kusheng Wu // Environmental Research. - 2014. - V. 128. - P. 84-91.

17. Temporal variation of total mercury levels in the hair of pregnant women from the Maternal-Infant Research on Environmental Chemicals (MIREC) study / A.O. Lukina, M. Fisher, Ch. Khoury, J. Than, M. Guay, J.-F. Paradis, T.E. Arbuckle, M. Legrand // Chemosphere. - 2021. - V. 264 (P. 1). - 128402.

18. Hui-Wen Hsiao, Ullrich S.M., Tanton T.W. Burdens of mercury in residents of Temirtau, Kazakhstan I: Hair mercury concentrations and factors of elevated hair mercury levels // Science of the Total Environment. - 2011. - V. 409. - P. 2272-2280.

19. Уровень биоэлементов в волосах и сыворотке крови у детей с расстройствами аутистического спектра / О.А. Денисенко, П.С. Новиков, Н.А. Черевко, А.Н. Кучер, Е.С. Ихалайнен, В.И. Отмахов, А.В. Обухова // Вестник Московского университета. Серия 2. Химия. - 2019. - № 3. - С. 198-203.

20. Hair trace element concentrations in autism spectrum disorder (ASD) and attention deficit/hyperactivity disorder (ADHD) / A.V. Skalny, A.L. Mazaletskaya, O.P. Ajsuvakova, G. Bjørklund, M.G. Skalnaya, S.V. Notova, L.N. Chernova, A.A. Skalny, T.I. Burtseva, A.A. Tinkov // Journal of Trace Elements in Medicine and Biology. - 2020. - V. 61. - 126539.

21. Bao-Qiang Guo, Hong-Bin Li, Ying-Ying Liu Association between hair lead levels and autism spectrum disorder in children: a systematic review and meta-analysis // Psychiatry Research. 2019. - V. 409. - P. 239-249.

22. Selenium content and/or T-2 toxin contamination of cereals, soil, and children's hair in some areas of Heilongjiang and Gansu Provinces, China / Liyan Sun, Silu Cui, Qing Deng, Hui Liu, Yanhong Cao, Shaoping Wang, Jun Yu // Biological Trace Element Research. - 2019. - V. 191. - P. 294-299.

23. Arsenic and selenium measurements in nail and hair show important relationships to Alzheimer's disease in the elderly / E. Koseoglu, B. Kutuk, O.U. Nalbantoglu, R. Koseoglu, M. Kendirci // Journal of Trace Elements in Medicine and Biology. - 2021. - V. 64. - 126684.

24. Levels of uranium and thorium in maternal scalp hair and risk of orofacial clefts in offspring / Yihui Wei, Lei Jin, Zhiwen Li, Jufen Liua, Linlin Wanga, Xin Pia, Shengju Yina, Chengrong Wanga, Aiguo Rena // Journal of Environmental Radioactivity. - 2019. V. 204. - P. 125-131.

25. Trace element biomonitoring in hair and blood of occupationally unexposed population residing in polluted areas of East Kazakhstan and Pavlodar regions / Y. Semenova, Y. Zhunussov, L. Pivina, A. Abisheva, A. Tinkov, T. Belikhina, A. Skalny, M. Zhanaspayev, T. Bulegenov, N. Glushkova, A. Lipikhina, M. Dauletyarova, T. Zhunussova, G. Bjørklund // Journal of Trace Elements in Medicine and Biology. - 2019. - V. 56. - P. 31-37.

26. In search of decoding the syntax of the bioelements in human hair - a critical overview / B. Momčilović, J. Prejac, A.V. Skalny, N. Mimica // Journal of Trace Elements in Medicine and Biology. - 2018. - V. 50. - P. 543-553. 
27. Changes in thallium distribution in the scalp hair after an intoxication incident / T. Matsukawa, M. Chiba, A. Shinohara, Y. Matsumoto-Omori, K. Yokoyama // Forensic Science International. - 2018. - V. 291. - P. 230-233.

28. Sukumar A. Hair elements for biomonitoring of human exposure, effects and health hazards // Encyclopedia of Environmental Health. - 2019. - V. 2. - P. 382-393.

29. Определение элементного статуса человека с целью оценки экологической безопасности регионов / В.И. Отмахов, А.В. Обухова, С.А. Ондар, Е.В. Петрова // Вестник Томского государственного университета. Химия. - 2017. - № 9. C. 50-59.

30. Наркович Д.В. Элементный состав волос детей как индикатор природно-техногенной обстановки территории (на примере Томской области): автореф. дис. ... канд. геол.-минерал. наук. - Томск, 2012. -21 c.

31. Determination of $\mathrm{Cl}, \mathrm{Br}$ and $\mathrm{I}$ in granola: development of an accurate analytical method using ICP-MS / G.T. Druzian, M.S. Nascimento, U.M.F.M. Cerqueira, C.G. Novaes, M.A. Bezerra, F.A. Duarte, E.M.M. Flores // Food Chemistry. 2021. - V. 344. - 128677.

32. Поцелуев А.А., Сарнаев С.И. Методические указания к выполнению цикла лабораторных работ с элементами научных исследований по курсу «Математические методы в геохимических исследованиях» для студентов специальности 08.01.04 (специализация геология и разведка месторождений радиоактивных и редких металлов). - Томск: Изд-во ТПУ, 1994. - 38 с.

33. Солевые образования питьевых вод как индикаторная среда в эколого-геохимических и металлогенических исследованиях / Б.Р. Соктоев, Л.П. Рихванов, Ш.Ж. Усенова, Т.А. Монголина, Н.В. Барановская // Вестник Иркутского государственного технического университета. Науки о Земле. - 2014. - Т. 84. № 1. - C. 40-44.

34. Рихванов Л.П. и др. Биогеохимический мониторинг в районах хвостохранилищ горнодобывающих предприятий с учетом микробиологических факторов трансформации минеральных компонентов. - Новосибирск: Изд-во СО РАН, 2017. - 437 с.

35. Влияние антропогенных геохимических факторов среды обитания на элементный статус детей п. Хапчеранга (Восточное Забайкалье) / Ю.А. Витковский, Л.А. Михайлова, Е.А. Бондаревич, М.А. Солодухина, Е.С. Эпова, О.В. Еремин, О.Г. Алексеева, Н.М. Бурлака, С.Э. Лапа, Н.В. Барановская, Е.В. Агеева // Забайкальский медицинский вестник. - 2018. - № 2. C. $14-23$.

36. Глазовская М.А. Геохимия природных и техногенных ландшафтов. - М.: Географический факультет МГУ, 1988. - 328 с.

Поступила 03.03.2021 г.

\section{Информация об авторах}

Байкенова $\boldsymbol{\Gamma . E . , ~ м а г и с т р ~ е с т е с т в е н н ы х ~ н а у к , ~ д о к т о р а н т ~ к а ф е д р ы ~ г е о г р а ф и и , ~ э к о л о г и и ~ и ~ т у р и з м а ~ К о к ш е т а у с к о - ~}$ го университета им. Ш. Уалиханова.

Барановская Н.B., доктор биологических наук, профессор отделения геологии Инженерной школы природных ресурсов Национального исследовательского Томского политехнического университета.

Какабаев A.A., кандидат биологических наук, доцент кафедры географии, экологии и туризма, советник ректора по международной интеграции Кокшетауского университета им. Ш. Уалиханова.

Берсимбаев Р.И., доктор биологических наук, академик НАН Республики Казахстан, профессор, заведующий кафедрой общей биологии и геномики Евразийского Национального университета им. Л.Н. Гумилева.

Корогод Н.П., кандидат биологических наук, доцент кафедры общей биологии Павлодарского педагогического университета.

Наркович Д.В., кандидат геолого-минералогических наук, доцент отделения геологии Инженерной школы природных ресурсов Национального исследовательского Томского политехнического университета.

Куровская B.B., инженер отделения нефтегазового дела Инженерной школы природных ресурсов Национального исследовательского Томского политехнического университета. 
UDC 574.2:550.47

\title{
INDICATORS OF THE STATE OF THE ECOSYSTEMS BASED ON THE HAIR COMPOSITIONS OF THE NORTHERN KAZAKHSTAN RESIDENTS
}

\author{
Gulim E. Baikenova1, \\ guliander@bk.ru
}

\section{Natalia V. Baranovskaya ${ }^{2}$,} nata@tpu.ru

\section{Anuarbek A. Kakabaev1, anuarka@mail.ru}

\section{Rakhmetkazhy I. Bersimbaev3,} ribers@mail.ru

\section{Natalya P. Korogod ${ }^{4}$,} natalya_korogod@mail.ru

\section{Dina V. Narkovich²,} narkovich@tpu.ru

\section{Vlada V. Kurovskaya ${ }^{2}$,} kurovskaya@tpu.ru

1 Sh. Ualikhanov Kokshetau University, 76, Abay street, Kokshetau, 020000, Republic of Kazakhstan.

2 National Research Tomsk Polytechnic University, 30, Lenin avenue, Tomsk, 634050, Russia.

3 L. Gumilev Eurasian National University, 13, Kazhymukana street, Nur-Sultan, 010008, Republic of Kazakhstan.

4 Pavlodar Pedagogical University, 60, Mira street, Pavlodar, 140002, Republic of Kazakhstan.

The relevance of the work is justified by the need to evaluate the environmental situation in the territories of uranium mining and other mining enterprises. Such region, with high morbidity and mortality of the population from malignant neoplasms, is Northern Kazakhstan. One of the largest provinces in the Kazakhstan is situated in the Northern Kazakhstan region - the North Kazakhstan uranium ore province. This province is located in the Akmola and North Kazakhstan regions. Hair, which is capable of depositing chemical elements in its structure, was used as a bioindicator of changes in the ecological and geochemical state of the territory.

Purpose: to evaluate the levels of accumulation of chemical elements in the hair of inhabitants of the Northern Kazakhstan regions.

Methods. 73 chemical elements in hair have been identified using inductively coupled plasma mass-spectrometry (ICP-MS).

Results. The content of elements in the inhabitant's hair of two regions of Northern Kazakhstan was studied and a comparative analysis with other territories of the region and individual regions of Russia was carried out. The analysis showed that in the Akmola and North Kazakhstan regions there was a high content of $\mathrm{Na}$, In, Te, Cs, Sm, Eu, Tb, Yb, Lu, Ta, Th, Hf and U. A general spectrum of elements characteristic of two regions of the North Kazakhstan: $\mathrm{Na}, \mathrm{Mg}$, Si, Ca. The following elements specific to the clarke noosphere in the Northern region: such as Bi, Au, S, Te, Re, $\mathrm{Ag}, \mathrm{Zn}, \mathrm{Se}, \mathrm{Ir}, \mathrm{I}, \mathrm{Cd}, \mathrm{Hg}$, were established. General spectrum of elements for all studied territories of Kazakhstan and Russia are $\mathrm{Au}, \mathrm{Ag}$, Se and $\mathrm{Hg}$.

\section{Key words:}

Bioindicator, hair, chemical elements, Northern Kazakhstan, elemental status, technogenesis.

The research was partially financially supported by the RSF grants no. 20-67-47005 and 20-67-47021 in analytical studies of samples from the territory of Chita region.

\section{REFERENCES}

1. Panin M.S. Ekologiya Kazakhstana [Ecology of Kazakhstan]. Semipalatinsk, SemGPU Publ, 2005. 548 p.

2. Kakabayev A.A. Tsitogeneticheskaya otsenka urovnya mutageneza u rabochikh uranodobyvayushchey promyshlennosti Severnogo Kazakhstana. Dis. Kand. nauk [Cytogenetic assessment of the level of mutagenesis in workers of the uranium mining industry in Northern Kazakhstan. Cand. Diss.]. Almaty, 2000. 125 p.
3. Berkinbayev G.D., Fedorov G.V., Bensman V.A. Obrashchenie s radioaktivnymi otkhodami v Kazakhstane [Radioactive waste management in Kazakhstan]. Ekologiya i promyshlennost Kazakhstana, 2013, no. 2 (38), pp. 42-49.

4. Kovalskiy V.V. Geokhimicheskaya sreda i zhizn [Geochemical environment and life]. Moscow, Nauka Publю, 1987.76 p.

5. Baranovskaya N.V., Shvetsova D.V., Rikhvanov L.P. Element content in children hair samples (Tomsk Region, Russia). Trace 
Elements in Human: New Perspectives: Proc. of the 7th Intern. Symp. Athens, Greece, 2009. pp. 290-303.

6. Sayet Yu.E., Revich B.A., Yanin E.P., Achkasov A.I., Basharkevich I.L., Onishchenko T.L., Pavlova L.N., Sarkisyan S.Sh., Smirnova R.S., Trefilova N.Ya. Geokhimiya okruzhayushchey sredy [Environmental geochemistry]. Moscow, Nedra Publ., 1990. $335 \mathrm{p}$.

7. Kist A.A. Fenomenologiya biogeokhimii $i$ bioneorganicheskoy khimii [Phenomenology of biogeochemistry and bioinorganic chemistry]. Tashkent, FAN Publ., 1987. 235 p.

8. Kist A.A., Zhuk L.I. Human hair composition and the problems of global ecology. Tashkent, USSR, Institute of Nuclear Physics of the Uzbek Academy of Sciences Publ., 1991. 60 p.

9. Ryabukhin Yu.S. Activation analysis of hair as an indicator of contamination of man by environmental trace element pollutants. Vienna, IAEA Publ., 1978. 134 p.

10. Element analysis of biological materials. Current problems and techniques with special reference to trace elements. App. II. Technical reports series. № 197. Vienna, IAEA Publ., 1980. pp. 351-367.

11. Narkovich D.V., Baranovskaya N.V., Koval E.V., Korogod N.P. Influence of technogenesis on forming element composition of childrens hair. Bulletin of the Tomsk Polytechnic University. Geo Assets Engineering, 2016, vol. 327, no. 8, pp. 116-128. In Rus.

12. Kumakli H., Duncan A.V., McDaniel K., Mehari T.F., Stephenson J., Maple L., Crawford Z., Macemore C.L., Babyak C.M., Fakayode S.O. Environmental biomonitoring of essential and toxic elements in human scalp hair using accelerated microwaveassisted sample digestion and inductively coupled plasma optical emission spectroscopy. Chemosphere, 2017, vol. 174, pp. 708-715.

13. Perez R., Suelves T., Molina Y., Corpas-Burgos F., Yusà V. Biomonitoring of mercury in hair of children living in the Valencian Region (Spain). Exposure and risk assessment. Chemosphere, 2019, vol. 217, pp. 558-566.

14. Yusà V., Pérez R., Suelves T., Corpas-Burgos F., Gormáz M. Dualde P., Coscolla C., Quiles J., Roca M., Vento M. Biomonitoring of mercury in hair of breastfeeding mothers living in the Valencian Region (Spain). Levels and predictors of exposure. Chemosphere, 2017, vol. 187, pp. 106-113.

15. Bravo M.A., Parra S., Quiroz W., Neaman A. Human exposure assessment to mercury through hair analysis in coastal villages of the Valparaiso region (Chile). Journal of the Chilean Chemical Society, 2019, vol. 64, pp. 4480-4483.

16. Wenqing Ni, Yaowen Chen, Yue Huang, Xiaoling Wang, Gairong Zhang, Jiayi Luo, Kusheng Wu. Hair mercury concentrations and associated factors in an electronic waste recycling rea, Guiyu, China. Environmental Research, 2014, vol. 128, pp. 84-91.

17. Lukina A.O., Fisher M., Khoury Ch., Than J., Guay M., Paradis J.-F., Arbuckle T.E., Legrand M. Temporal variation of total mercury levels in the hair of pregnant women from the Maternal-Infant Research on Environmental Chemicals (MIREC) study. Chemosphere, 2021, vol. 264 (P. 1). 128402.

18. Hui-Wen Hsiao, Ullrich S.M., Tanton T.W. Burdens of mercury in residents of Temirtau, Kazakhstan I: hair mercury concentrations and factors of elevated hair mercury levels. Science of the Total Environment, 2011, vol. 409, pp. 2272-2280.

19. Denisenko O.A., Novikov P.S., Cherevko N.A., Kucher A.N., Ikhalainen E.S., Otmakhov V.I, Obukhova A.V. The level of bioelements in hair and blood serum in children with autism spectrum disorders. Herald of Moscow University. Series 2. Chemistry, 2019 no. 3, pp. 198-203. In Rus.

20. Skalny A.V., Mazaletskaya A.L., Ajsuvakova O.P., Bjørklund G., Skalnaya M.G., Notova S.V., Chernova L.N., Skalny A.A., Burtseva T.I., Tinkov A.A. Hair trace element concentrations in autism spectrum disorder (ASD) and attention deficit/hyperactivity disorder (ADHD). Journal of Trace Elements in Medicine and Biology, 2020, vol. 61. 126539.

21. Bao-Qiang Guo, Hong-Bin Li, Ying-Ying Liu. Association between hair lead levels and autism spectrum disorder in children: a systematic review and meta-analysis. Psychiatry Research, 2019, vol. 276, pp. 239-249

22. Liyan Sun, Silu Cui, Qing Deng, Hui Liu, Yanhong Cao, Shaoping Wang, Jun Yu. Selenium content and/or T-2 toxin contamination of cereals, soil, and children's hair in some areas of Heilongjiang and Gansu Provinces, China. Biological Trace Element Research, 2019, vol. 191, pp. 294-299.
23. Koseoglu E., Kutuk B., Nalbantoglu O.U., Koseoglu R., Kendirci M. Arsenic and selenium measurements in nail and hair show important relationships to Alzheimer's disease in the elderly. Journal of Trace Elements in Medicine and Biology, 2021, vol. 64. 126684.

24. Yihui Wei, Lei Jin, Zhiwen Li, Jufen Liua, Linlin Wanga, Xin Pia, Shengju Yina, Chengrong Wanga, Aiguo Rena. Levels of uranium and thorium in maternal scalp hair and risk of orofacial clefts in offspring. Journal of Environmental Radioactivity, 2019, vol. 204, pp. 125-131.

25. Semenova Yu., Zhunussov Y., Pivina L., Abisheva A., Tinkov A., Belikhina T., Skalny A., Zhanaspayev M., Bulegenov T., Glushkova N., Lipikhina A., Dauletyarova M., Zhunussova T., Bjørklund G. Trace element biomonitoring in hair and blood of occupationally unexposed population residing in polluted areas of East Kazakhstan and Pavlodar regions. Journal of Trace Elements in Medicine and Biology, 2019, vol. 56, pp. 31-37.

26. Momčilović B., Prejac J., Skalny A.V., Mimica N. In search of decoding the syntax of the bioelements in human hair - a critical overview. Journal of Trace Elements in Medicine and Biology, 2018, vol. 50, pp. 543-553

27. Matsukawa T., Chiba M., Shinohara A., Matsumoto-Omori Y., Yokoyama K. Changes in thallium distribution in the scalp hair after an intoxication incident. Forensic Science International, 2018, vol. 291, pp. 230-233.

28. Sukumar A. Hair elements for biomonitoring of human exposure, effects and health hazards. Encyclopedia of Environmental Health, 2019, vol. 2, pp. 382-393.

29. Otmakhov V.I., Obuhova A.V., Ondar S.A., Petrova E.V. Determining people's element status to assess the ecological safety of regions. Tomsk State University Journal. Chemistry, 2017, no. 9, pp. 50-59. In Rus.

30. Narkovich D.V. Elementny sostav volos detey kak indikator prirodno-tekhnogennoy obstanovki territorii (na primere Tomskoy oblasti). Avtoreferat Dis. Kand. nauk [Elemental composition of children's hair as an indicator of the natural and technogenic situation of the territory (the case of of the Tomsk region) Cand. Diss. Abstract]. Tomsk. 2012. $21 \mathrm{p}$

31. Druzian G.T., Nascimento M.S., Cerqueira U.M.F.M., Novaes C.G., Bezerra M.A., Duarte F.A., Flores E.M.M. Determination of $\mathrm{Cl}$, $\mathrm{Br}$ and $\mathrm{I}$ in granola: development of an accurate analytical method using ICP-MS. Food Chemistry, 2021, vol. 344. 128677.

32. Potseluev A.A., Sarnaev S.I. Metodicheskie ukazaniya $k$ vypolneniyu tsikla laboratornykh rabot s elementami nauchnykh issledovaniy po kursu «Matematicheskie metody v geokhimicheskikh issledovaniyakh» dlya studentov spetsialnosti 08.01 .04 (spetsializatsiya geologiya $i$ razvedka mestorozhdeniy radioaktivnykh $i$ redkikh metallov) [Methodical instructions for performing a cycle of laboratory work with elements of scientific research in the course «Mathematical methods in geochemical research» for students of the specialty 08.01 .04 (specialization in geology and exploration of deposits of radioactive and rare metals)]. Tomsk, TPU Publ., 1994. 38 p.

33. Soktoev B.R., Rikhvanov L.P., Usenova Sh.Zh., Mongolina T.A., Baranovskaya N.V. Drinking water salt sediments as indicative media in ecogeochemical and metallogenic researches. Bulletin of Irkutsk State Technical University. Earth Sciences, 2014, vol. 84, no. 1, pp. 40-44. In Rus.

34. Rikhvanov L.P. Biogeokhimicheskiy monitoring $v$ zonakh khvostokhranilishch gornodobyvayushchikh predpriyatiy $s$ uchetom mikrobiologicheskikh faktorov transformatsii mineralnykh komponentov [Biogeochemical monitoring of tailings of mining industry, taking into account microbiological factors of the mineral component transformation]. Novosibirsk, SB RAS Publ., 2017. 437 p.

35. Vitkovsky Y.A., Mikhaylova L.A., Bondarevich E.A., Solodukhina M.A., Epova E.S., Eremin O.V., Alekseeva O.G., Burlaka N.M., Lapa S.E., Baranovskaya N.B., Ageeva E.V. Influence of anthropogenous geochemical habitat factors on elemental status of children living in Khapcheranga village (Eastern Transbaikalia). Transbaikal Medical Bulletin, 2018, no. 2, pp. 14-23. In Rus.

36. Glazovskaya M.A. Geokhimiya prirodnykh i tekhnogennykh landshaftov [Geochemistry of natural and technogenic landscapes]. Moscow, Geography Faculty of Moscow State University Publ., 1988. $328 \mathrm{p}$. 
Information about the authors

Gulim E. Baikenova, master, doctoral student, Sh. Ualikhanov Kokshetau University.

Natalia V. Baranovskaya, Dr. Sc., professor, National Research Tomsk Polytechnic University.

Anuarbek A. Kakabayev, Cand. Sc., associate professor, Sh. Ualikhanov Kokshetau University.

Rakhmetkazhy I. Bersimbaev, Dr. Sc., professor, academician of NASRK, L. Gumilev Eurasian National University. Natalya P. Korogod, Cand. Sc., associate professor, Pavlodar Pedagogical University.

Dina V. Narkovich, Cand. Sc., associate professor, National Research Tomsk Polytechnic University.

Vlada V. Kurovskaya, engineer, National Research Tomsk Polytechnic University. 